\title{
The need for training dentists for dental care for people with autism spectrum disorder
}

Lais David AMARAL'; Tatiana Degani Paes Leme AZEVEDO; Francine do Couto Lima MOREIRA2 ${ }^{\mathbb{D}}$; Adriano de Almeida de LIMA3; Ana Cristina Barreto BEZERRA ${ }^{3}$

1 - Universidade Católica de Brasília - UCB, Escola de Saúde e Medicina, Faculdade de Odontologia; 2 - Universidade Federal de Goiás - UFG, Faculdade de Odontologia; 3 - Universidade de Brasilia - UnB, Centro de Ciências da Saúde, Faculdade de Odontologia.

\begin{abstract}
Aims: This study aimed to investigate dentist satisfaction, participation in training courses, performance in primary health care services, and the inclusion of people with Autism Spectrum Disorder (ASD) in dental office. Material and Methods: 58 dentists completed a questionnaire entitled "Implementing a Systematization of Oral Healthcare for People with ASD to Primary Care Professionals of the Health System" that had four parts, and investigated the professional satisfaction, participation in courses, performance in primary health care services in public health and the inclusion of dental care for people with ASD. Results: $65.5 \%$ of professionals participated in training courses. Dentists who took the courses on the patients with special needs claimed that they treated significantly more patients with ASD $(\mathrm{p}$-value $=0.003)$ and indicated periodontal disease and caries as the most frequent problems. However, $89.6 \%$ were unaware of a document with clinical practice guidelines for autistic patients, reinforcing the need for professional training. Conclusion: Dentists were aware of the importance of training and were willing to undergo courses that could improve their professional performance to promote the oral health of patients with ASD.
\end{abstract}

KEYWORDS: Autism Spectrum Disorder; Dentistry; Public Health Professional; Education. 


\section{Introduction}

Autism Spectrum Disorder (ASD) was first described in 1943 by the psychiatrist Leo Kanner. According to the American Psychiatric Association ${ }^{1}$, it is defined as a neurodevelopmental disorder, characterized by a lack of adaptation, which manifests in a critical manner throughout the individual's lifetime, in the Diagnostic and Statistical Manual of Mental Disorders. The signs usually manifest early (up to 6 months of age); however, they may fully manifest later in life when social demands exceed the limited capacities of the affected individuals and cannot be masked by strategies learned to overcome these limitations ${ }^{2-4}$.

ASD affects approximately $1 \%$ of the population in the United States and other countries, with similar incidences in children and adults ${ }^{1}$.

Considering the difficulties faced by these individuals and the limitations that this condition imposes on their families; the common activities of daily lives are often compromised both in quality and quantity for patients with ASD. Therefore, health professionals must carry out frequent follow-ups for these individuals ${ }^{5,6}$.

Identifying and seeking solutions for oral health problems in these individuals require a trained dentist, who is willing to carry out these tasks. They should be on a constant look out for new approaches to modify procedures to accommodate the needs of the ASD patient, allowing more effective attendance and reducing the burden and stress faced by these individuals and their families ${ }^{7-9}$.

If dentists are aware of the clinical manifestations of ASD, such as behavioral changes, fear of noises, fear of the unknown, preference for solitude, and inability to interact with people, when treating these patients, dental treatments can be modified to accommodate the patients' needs; this increases the treatment's probability of success. These clinical manifestations represent 
the most significant challenges in the oral care of people with ASD $^{6,10,11}$.

Communication with patients establishes a therapeutic relationship between the patient and the dentist; this should be utilized during all dental procedures for ASD patients to ensure successful completion of the procedure. This would enable successful completion of the dental treatment. Thus, limiting the use of advanced techniques such as sedation, general anesthesia, and protective stabilization to only extreme cases ${ }^{10,12-14}$.

Systematic desensitization and psychological approaches, including management techniques, behavior control, and using communication methods such as the Picture Exchange Communication System can be used to condition the behavior of patients who experience anxiety in a dental office $\mathrm{e}^{15-17}$. During these procedures, patients are gradually exposed to different components of a dental office, and over time, after familiarization and successful interactions with a dentist, patients with ASD become comfortable and cooperate with the dental treatment ${ }^{15-19}$.

Oral conditions commonly found in patients with ASD include periodontal problems, malocclusion, minor salivary flow and xerostomia, gingival recessions, and cavities, especially in occluso-proximal surfaces and cervical regions of vestibular surfaces ${ }^{20}$.

Studies have indicated that these conditions result from insufficient maintenance of oral hygiene in the patients, which occurs due to the difficulties of motor coordination, behavioral and intellectual impairment, lack of patient collaboration, lack of proper guidance to caregivers, and the use of medications such as anxiolytics and anticonvulsants t,7,21,22 $_{\text {. }}$

In Brazil, the Unified Health System (SUS) guarantees free health care for the entire population and involves promotion, 
protection, and recovery of health, which form an indivisible whole that should not be compartmentalized ${ }^{23,24}$.

Dentists working in public health services should treat patients with ASD in their own social and housing context, which would allow the implementation of comprehensive care. In addition, these professionals should be familiar with the stomatological manifestations found in individuals with special needs, including ASD, to provide efficient treatment that is tailored to the needs of this population ${ }^{6}$.

However, the reality of public services in Brazil is far from ideal. The lack of dentists results in an overloaded system that is unable to meet the demands of the population ${ }^{25,26}$.

This study presents data on the current scenario of dental care for patients with ASD and seeked to identify areas of improvement. Targeted improvement in these areas would ensure an equitable, gratuitous, and universal dental care system that caters to the requirements of the people who are excluded from the prevailing system. This study aimed to investigate professional satisfaction, participation in training courses, performance in primary health care services, and the inclusion of people with ASD in dental office among dentists of Natal city.

\section{Material and methods}

\section{Validation of the questionnaire}

A structured questionnaire (Table 1) was developed using the Likert scale with the options to be indicated by the participants. The questionnaire was completed, at two different time points during the validation stage, by distinct groups of 20 dentists who participated in the pilot study. This allowed determination of items that presented inconsistencies and implementation of necessary adjustments, which was followed by validation of this instrument by new statistical tests using Cronbach's alpha ${ }^{27}$. 
TABLE 1 - Research instrument: Questionnaire applied to dentists who work in primary health care service of the public sector, in the city of Natal-RN, Brazil.

\section{Registration Form}

The institution where I work

\begin{tabular}{lllll}
\hline Location & $\begin{array}{l}\text { Period of } \\
\text { employment }\end{array}$ & Working hours & Courses offered & $\begin{array}{c}\text { Participation in } \\
\text { courses }\end{array}$ \\
\hline Job Satisfaction & & & $\begin{array}{l}\text { Motivation to } \\
\text { participate in } \\
\text { courses }\end{array}$ \\
\hline Motivation & Salary satisfaction & Working conditions & $\begin{array}{l}\text { Relations with } \\
\text { coworkers }\end{array}$ & Amount of Work \\
\hline
\end{tabular}

\section{Performance in public health services}

\begin{tabular}{|c|c|c|c|c|}
\hline $\begin{array}{l}\text { The existence of } \\
\text { a protocol for oral } \\
\text { health care of people } \\
\text { with special needs. }\end{array}$ & $\begin{array}{l}\text { The existence of } \\
\text { a protocol for oral } \\
\text { health care of people } \\
\text { with autism }\end{array}$ & Home visits & $\begin{array}{l}\text { Priorities in home } \\
\text { visits }\end{array}$ & Activities carried out in home visits \\
\hline
\end{tabular}

Dental care for patients with autism - applied to 19 professionals who answered affirmatively about attending people with ASD in their clinical practices

\begin{tabular}{|c|c|c|c|c|c|}
\hline $\begin{array}{l}\text { Reasons for the first } \\
\text { visit }\end{array}$ & Main oral problems & Frequent treatments & $\begin{array}{l}\text { Management for } \\
\text { anxiety control }\end{array}$ & $\begin{array}{l}\text { Participation of } \\
\text { caregivers }\end{array}$ & $\begin{array}{l}\text { Main aspects for } \\
\text { attending patients } \\
\text { with ASD }\end{array}$ \\
\hline
\end{tabular}

The final statistical validation of this research instrument showed that the scale used for measuring the responses of dentists, involved in primary health care in Natal, on the importance of accommodating patients with ASD in their work units had a high level of internal consistency (0.962).

\section{Participants}

Natal is a municipality located in the northeast of Brazil; it is the capital of the State of Rio Grande do Norte, has an area of $163 \mathrm{~km}^{2}$, and an estimated population of 803,739 inhabitants according to the Brazilian Institute of Geography and Statistics ${ }^{28}$.

According to IBGE ${ }^{28}$, Rio Grande do Norte is one of the Brazilian States with the highest percentage of population with one or more types of disabilities, which account for $27.8 \%$ of the total state population. 
The study was conducted through a census, and all 115 dentists working in the primary care sector of the public health network at Natal-RN were invited to participate. In total, 58 professionals working in the family health strategy (FHS) agreed to cooperate. Each professional completed a questionnaire entitled "Implementing a Systematization of Oral Healthcare for People with Autism to Primary Care Professionals of the Health System" that had four parts. Only 19 professionals answered the last part of the questionnaire, which contained questions related specifically to the dental care of patients with ASD. All 19 professionals had undergone $8 \mathrm{~h}$ long specific training, which included lectures covering the definition of ASD and suggestions, based on scientific studies, on how to modify and adapt procedures used in primary health care to better meet the needs of ASD patients and ensure preservation of their quality of life and oral health.

\section{Statistical analysis}

The study was divided into descriptive and analytical parts. Considering that the main objective of this study was to evaluate dentists ' ability to care for patients with ASD, they were divided into "attends" and "do not attend." The statistical association of categorical variables in these groups was evaluated using a Pearson's chi-square test with continuity correction when necessary. To evaluate the association of numeric variables in the "attends" and "do not attend" groups, a student's t-test was used. Descriptive analysis of absolute frequency (n) and relative percentage (\%) for the qualitative variables was also performed. The quantitative variables were presented as the following measures: mean, standard deviation, and minimum and maximum values. Linear regression analysis was performed to identify the variables that interfered with the responses to the questionnaire, which were divided into four groups: institution where they worked, job satisfaction, performance in public health services, and attending patients with ASD. For defining a value for 
each of these variables, the average of the responses was converted to a scale of 0 to 10 for easier understanding. Therefore, for some questions, it was necessary to reverse the numbering to standardize the results. The data analyses were carried out using IBM SPSS software 21, 2012. A significance level of 5\% was used for this study.

\section{Compliance with ethical standards}

This study was approved by the Committee on Ethics and Research in human beings from the Faculty of Health Sciences of the University of Brasilia, through the Brazil Platform (process: 23451613.1.0000.0030), and was performed in accordance with the ethical standards defined in the 1964 Declaration of Helsinki and its later amendments or comparable ethical standards.

\section{Results}

Regarding the institution where the participants worked The sample consisted of 58 professionals with a mean age of $41.02( \pm 10.35)$ years, and the majority were females $(73.5 \%)$. The average duration since graduation was 17 years. The dentists had been working for an average of $9.83(+6.82)$ years in the FHS, with an average hourly load of $39.62(+2.75)$ h/week.

When questioned about participation in training and specialization courses offered free of charges by SUS, through the Open University of the SUS - UNA-SUS, 38 (65.5\%) professionals answered positively about participating in these courses. Among these 38 participants, $46.3 \%$ had undergone the specialization training course on family health and only $22.4 \%$ had participated in the updated course on the patients with special needs. Figure 1 shows the UNA-SUS training courses that the participants had undergone.

The average of the responses for participation in courses, converted to a scale of 0 to 10 , was $7.79(+1.53)$. Therefore, it was 
perceived that the professionals and the institution were motivated to carry out courses/training.

The total number of participants mentioned in Figure 1 is more than 58 as the professionals could mark more than one alternative.

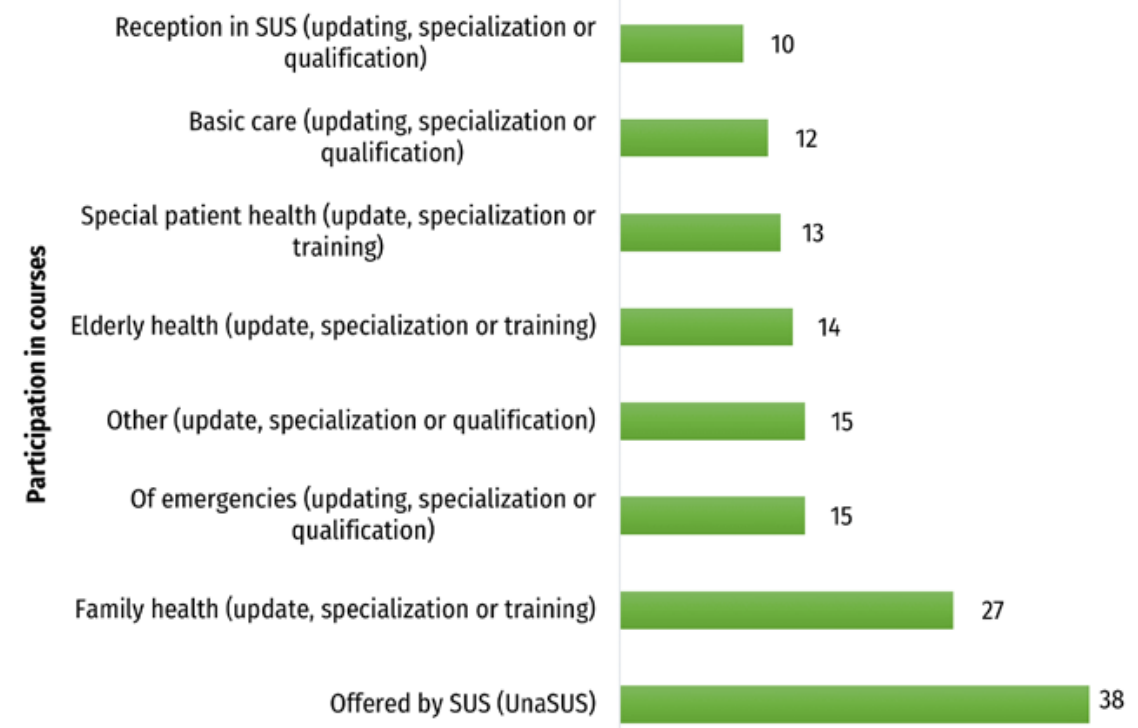

FIGURE 1 - Participation in courses carried out by dentists who work in the primary health care service of the public sector in city of Natal - RN, Brazil

\section{Regarding professional satisfaction}

The average of the responses for professional satisfaction, converted to a scale of 0 to 10 , was $6.01(+1.23)$, which was considered an average result.

Regarding the performance in public services

When participants were questioned about their performance in health services, the results obtained were average. The average of the responses, converted to a scale of 0 to 10 , was $5.87(+1.54)$.

On questioning about the existence of a protocol or document with guidelines on dental care for patients with special needs in the primary health care unit, $48(82.8 \%)$ professionals gave a negative response. Furthermore, $52(89.6 \%)$ participants gave a 
negative response when probed about the existence of a similar protocol or document in their workplace (Table 2).

Concerning the performance of these professionals in the FHS and home care, 52 participants (89.6\%) replied positively. They confirmed conducting these visits, particularly for patients with motor impairments or those who were bedridden, elderly, and pregnant (Figure 2).

TABLE 2 - Qualitative variables on the awareness of protocols or guidelines for the dental care of people with special needs and people with ASD, intended for dentists who work in the primary health care service of public sector in the city of Natal-RN, Brazil.

$\begin{array}{lll}\text { Variable } & \text { n } & \%\end{array}$

Awareness of protocols for the care of people with special needs

\begin{tabular}{lcc}
\hline Yes & 1 & 1,7 \\
\hline No & 48 & 82,8 \\
\hline Could not answer & 9 & 15,5 \\
\hline
\end{tabular}

Awareness of protocols for the care of people with autism

\begin{tabular}{lll}
\hline No & 52 & 89,6 \\
\hline Could not answer & 6 & 10,4 \\
\hline
\end{tabular}

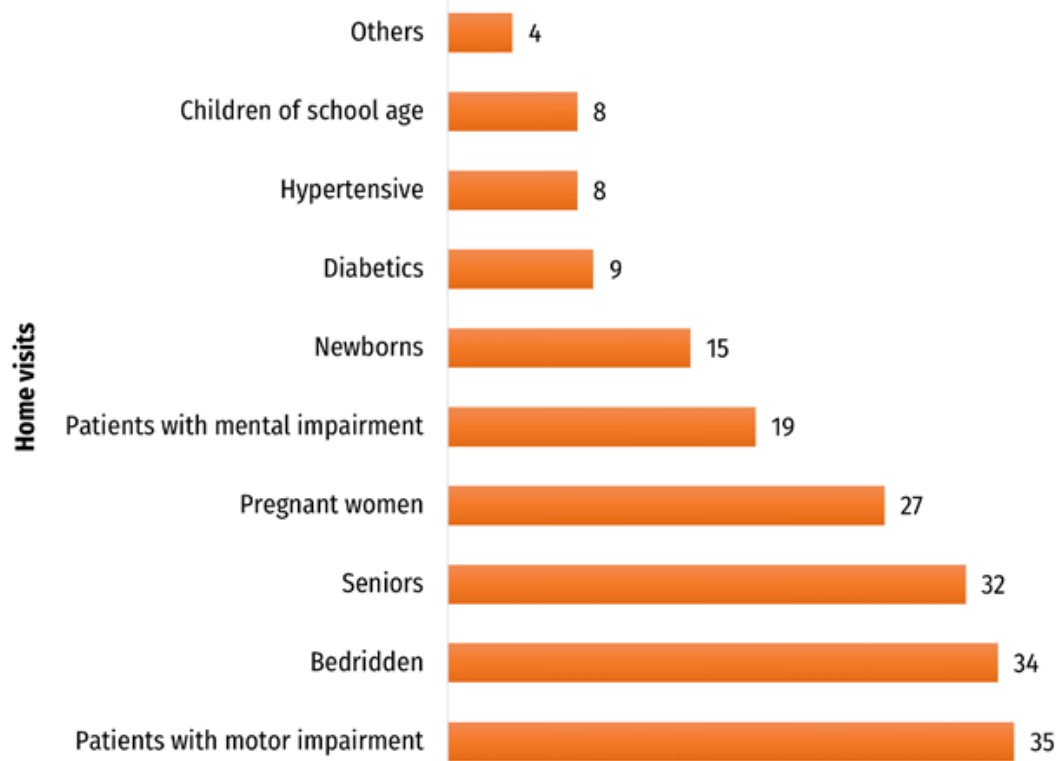

FIGURE 2 - Home visits performed by dentists who work in the FHS of the public sector of the city of Natal-RN, Brazil 


\section{Regarding the dental care for patients with asd}

Among the participants, only 19 (35.8\%) responded that they treated patients with ASD routinely.

According to these professionals, the primary reasons for dental consultations were carious teeth (68.4\%) and pain (57.9\%) (Figure 3 ).

The main problems found in the oral cavity of patients with ASD were the presence of plaque (78.9\%), dental calculus (73.7\%), tooth decay (68.4\%), and poor hygiene (63.3\%) (Figure 4 ).

Some of the most frequently performed treatments were prophylaxis for mechanical removal of plaque (84.2\%), calculus scraping (78.9\%), and restorations of posterior teeth (63.2\%) (Figure 5).

On questioning about the most important facilitator for oral health care in people with ASD, establishment of a relationship of trust (100\%), presence of a caregiver (57.9\%), and desensitization to the dental environment (42.1\%) were found to be the most important tools for treating these patients. Only four professionals answered that protective stabilization was crucial to the success of the treatment (Figure 6).

For statistical evaluation of the association between the variables studied in the questionnaire and the care given to patients with ASD, the professionals were divided into groups of "attend" and "do not attend" based on whether they treat ASD patients. The most significant statistical association was found with participation in training on the health of patients with special needs $(\mathrm{p}=0.003)$. Dentists who underwent training on the health of patients with special needs attended significantly more patients with ASD than those who did not, which highlights the importance of conducting these trainings for the health professionals working in the FHS (Table 3).

The average of the responses for the care of patients with ASD, converted to a scale of 0 to 10 , was $5.13(+1.58)$. 
TABLE 3 - Association between qualitative variables on professional performance and courses taken in relation to the attendance or non-attendance to patients with ASD by dentist who work in the primary care service of the public sector in the city of Natal-RN, Brazil.

\begin{tabular}{llll}
\hline Variable & Attends & Do not attend & p-value \\
\hline Participated in Una-SUS courses & & & \\
\hline Yes & 11 & 27 & 0,394 \\
\hline No & 8 & 12 & \\
\hline
\end{tabular}

\section{Participated in course on the health of patients with special needs}

\begin{tabular}{lccc}
\hline Yes & 9 & 4 & 0,003 \\
\hline No & 10 & 35 & \\
\hline
\end{tabular}

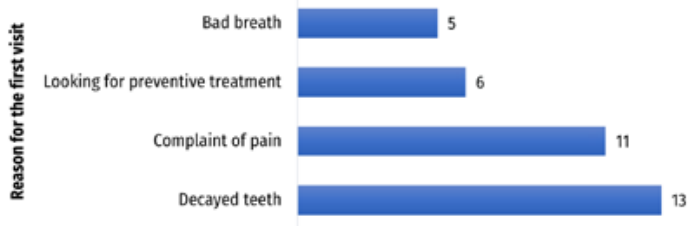

FIGURE 3 - Reasons for the first visit of patients with ASD performed by dentists who work in the primary health care service of the public sector in the city of Natal-RN, Brazil

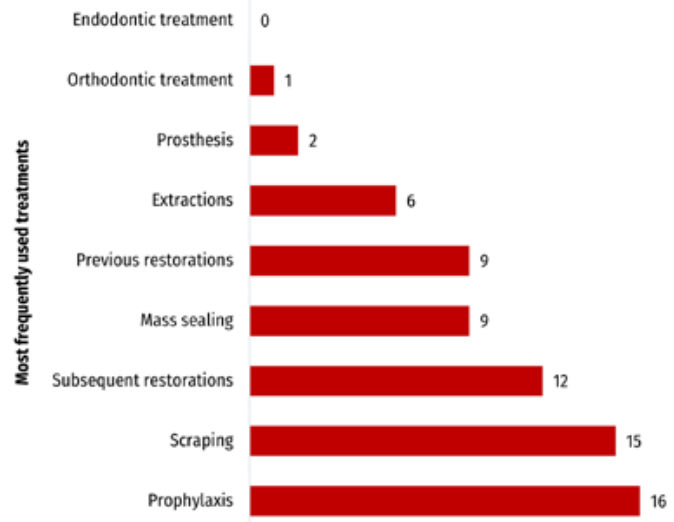

FIGURE 5 - Dental procedures performed most frequently in the care of patients with ASD by dentists who work in the primary health care service of the public sector in the city of Natal-RN, Brazil

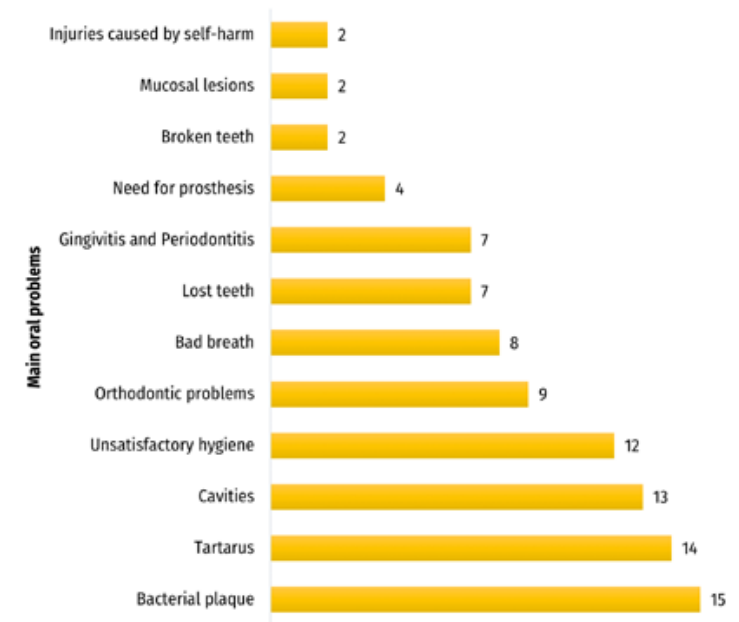

FIGURE 4 - Main problems found in the care of patients with ASD performed by dentists who work in the primary health care service of the public sector in the city of Natal-RN, Brazil

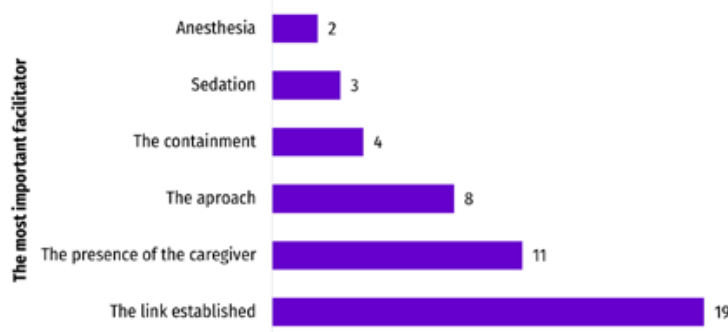

FIGURE 6 - Most important facilitating resource in the care of patients with ASD according to dentists who work in the primary health care service of the public sector in the city of Natal-RN, Brazil 


\section{Discussion}

Oral health is a determining factor for the quality of life of patients with autism. According to the study conducted by Nilchian et al. ${ }^{19}$ (2017), children with autism reported with more carious teeth than those without autism. This may be attributed to the difficulty in collaboration during dental sessions, which may postpone the dental treatment.

Inappropriate eating habits, such as eating sweets and sticky foods, and keeping them in the oral cavity for long durations (especially in the vestibule region), also contribute to an unsatisfactory oral health condition ${ }^{5}$. Parents and caregivers act as protagonists for promoting the health of their children when they are aware of the existing problems and are instructed on how to solve them. Thus, dentists should be prepared to meet the oral needs of patients with autism and guide parents and caregivers appropriately.

This study conducted a survey involving 58 dentists operating in the primary health care sector, investigating the inclusion of people with autism in their clinical practice. On analyzing the first variable, referring to the institution where the professional worked, it was observed that dentists performed their duties in the FHS for an average of 10 years. A large proportion of the sample also conducted training courses promoted by the Una-SUS.

Una-SUS is a system created in 2010 with the aim of meeting the needs of training and continuing education of professionals working in the Brazilian public health system, coordinated by the Ministry of Health. Educational trainings are free of charge and cover $98 \%$ of Brazilian municipalities and $50 \%$ of trained professionals working in the primary health care sector. They are aimed at promoting the quality of healthcare services. The courses occur either face-to-face or online and include specializations, qualifications, and enhancements. The Ministry of Health conducts these courses in partnership with 
federal universities that are committed to high-quality teaching and scientific evidence ${ }^{29}$.

The linear regression analysis demonstrated a high participation in these courses (7.79), which may be attributed to the ease and/or gratuity of the courses and their high quality. However, the courses related to the care of people with special needs were attended only by a small number of dentists. This result can be justified by the shortage of training courses involving dentistry for people with special needs. According to Una-SUS data available on the Arouca platform, only two courses conducted between 2013 and 2017, with a partnership of a university located in the northeast of Brazil, offered training for health care and oral health care for people with special needs. These courses received a total of 12,000 subscribers and were held on a digital platform. In comparison, in the same period, specialization courses in family health were offered 132 times, involving 14 partner universities across the country ${ }^{30}$.

The linear regression analysis showed a value of 6.01 for job satisfaction among the evaluated dentists. In the current health care scenario in Brazil, initiatives to strengthen primary health care and the reorganization of health services are based on constitutional principles. However, working in the health sector implies to establish a relationship between professionals and users of the services and their families, bringing dentists closer to the problems experienced by assisted households. Lima et al. ${ }^{31}$ (2014) conducted a study on the satisfaction of professionals working in the primary health care in Brazil and showed that $18.18 \%$ of the participants were satisfied with the assistance offered in the services provided. Gomes et al. ${ }^{32}$ (2010) concluded that excessive workload, low wages, physical weariness, and the appreciation received in the private sector at the expense of those in the public sector are the main causes of professional dissatisfaction among dentists working in public services. 
The data from the present study showed that most professionals $(89.6 \%)$ perform home visits for those with special needs. However, as seen in Figure 2, these visits do not include people with autism. The lack of training in dental care for patients with autism can justify these results and may contribute to the worsening of the oral conditions of this population.

Among the participants of the study, only $35.8 \%$ claimed to have attended to patients with ASD. They reported that the most frequent oral problems in this population were periodontal disease and caries (Figure 4). These results are in agreement with those of Orellana et al. ${ }^{5}$ (2014), Amaral et al. ${ }^{6}$ (2016), and Nilchian et al. ${ }^{19}(2017)$.

Corroborating the results shown in Figure 6, the most important item was the establishment of trust between the patients with ASD and their caregivers, and the dentist (100\% of the sample). A study prioritized the use of socio-behavioral interventions, emphasizing the relationship established between professionals, patients with autism, and caregivers ${ }^{14}$. Thus, these professionals should recognize the importance and the possibility of carrying out these services at the primary level of health care, considering that not all cases are indicated for secondary and tertiary care ${ }^{14}$.

Multiple linear regression analysis showed negative results for all variables related to the use of sedation in the care of patients with autism as the main facilitator. Although some studies, especially those performed in the United States and the United Kingdom ${ }^{7,10}$, emphasized the requirement of sedation and general anesthesia for dental care of patients with autism, the group of professionals participating in this research was apparently reluctant with using this practice. In agreement with the results presented in this study, Mathu-Muju et al. ${ }^{13}$ (2016) emphasized the importance of a careful evaluation of the severity of neurological disorders in patients with autism before scheduling them for procedures under general anesthesia because such 
patients may present a potential ability to cooperate with dental treatments, provided that appropriate behavioral guidance techniques are used.

According to some studies ${ }^{8,9,19}$ the dental care of an autistic patient should be based on appropriate training of caregivers and family members, as well as appropriate oral hygiene techniques and healthy diets. Dentists should closely monitor these families, modify their inadequate conducts, and promote oral health activities during home visits ${ }^{5,8,32}$. The main cause of the shortage in the reception of people with autism by oral health care teams in the primary care setting is the lack of professional knowledge and qualification regarding the condition of these patients.

In conclusion, despite facing difficulties regarding professional satisfaction and performance in public health services, the dentists included in this study were aware of the importance of training and were willing to undergo courses that could improve their professional performance. Most participants did not receive adequate guidance on practices involving patients with special needs, including those with ASD, and were unaware of information that could assist them in this approach. Thus, these documents should not only be made available but should also be readable and comprehensive for dentists in the primary health care sector. Furthermore, courses and guidelines should be offered to dentists to promote the oral health of patients with ASD, reinforcing the importance of investing in professional training.

\section{References}

1 - American Psychiatric Association. Diagnostic and statistical manual of mental disorders, 5th ed. Washington, DC: American Psychiatric Association; 2013.

2 - Macfabe D. Autism: metabolism, mitochondria, and the microbiome. Global Adv Health Med. 2013; 2(6):52-66.

3 - Mazurek M, Kager M, Van Hooser,SD. Robust quantification of orientation selectivity and direction selectivity. Front Neural Circuits. 2014; 8: 92. 
4 - Croen LA, Shankute N, Davignon M, Massolo ML, Yoshida C. Demographic and Clinical Characteristics Associated with Engagement in Behavioral Health Treatment Among Children with Autism Spectrum Disorders. J Autism Dev Disord. 2017; 47(11): 3347-3357.

5 - Orellana LM, Martínez-Sanchis S, Silvestre FJ. Training Adults and Children with an Autism Spectrum Disorder to be Compliant with a Clinical Dental Assessment Using a TEACCH-Based Approach. J Autism Dev Disord. 2014; 44(4): 776-785.

6 - Amaral LD, Carvalho TF, Bezerra ACB. Bioethics Focus to autistics vulnerability: the dental care in family health strategies. Rev Latinoam Bioet. 2016; 16(1): 220-233.

7 - U.S. Department of Health and Human Services [homepage on the internet]. Practical Oral Care for People with Autism [Cited 2016 May 12]. Available from: http://www.nidcr.nih.gov

8 - Wiener C, Vohra R, Sambamoorthi U, Madhavan SS. Caregiver Burdens and Preventive Dental Care for Children with Autism Spectrum disorder, developmental disability and/or mental health conditions: National Survey of CSHCN, 2009-10 Matern Child Health J. 2016; 20(2): 2573-2580.

9 - Tong HJ, Lee HY, Lee YT, Low Y, Lim CR, Nair R. Factors influencing the inclusion of oral health education in individualized education plans of children with autism spectrum disorders in Singapore. Int J Paediatr Dent. 2017; 27(4):255-263.

10 - Friedlander AH, Yagiela JA, Paterno VI. The pathophysiology, medical management and dental implications of fragile X, Rett and PraderWilli syndromes. J. Calif Dent Assoc. 2003; 31(9): 693-702.

11 - Blomqvist M, Bejerot S, Dahllöf G. A Cross Sectional Study on Oral Health and Dental Care in Intellectually Able Adults with Autism Spectrum Disorder. BMC Oral Health 2015; 15:81-88.

12 - Waldman HB, Perlman SP, Wong AJ. Providing dental care for the patient with autism. Calif Dent Assoc. 2008; 36(9): 662-670.

13 - Mathu-Muju KR, Hsin-Fang L, Nam LH, Bush HM. Visualizing the Comorbidity Burden in Children with Autism Spectrum Disorder Receiving Dental Treatment Under General Anesthesia. Pediatric Dentistry. 2016; 38(2):134-139.

14 - Elmore JL, Bruhn AM, Bobzien JL. Interventions for the Reduction of Dental Anxiety and Corresponding Behavioral Deficits in Children with Autism Spectrum Disorder. J Dent Hyg. 2016; 90(2): 111-20.

15 - Czornobay LFM, Munhoz EA, Lisboa ML, Rath IBS, Camargo AR. Autism spectrum disorder: Review of literature and dental management. World J Stomatol. 2018; 6(2): 11-18.

16 - Moreira FCL, Martorell LB, Guimarães MB, Dias AD, Consorte LCJ. Use of TEACCH program as a coadjuvant to dental care in patients with autism: case report. Sci Invest Dent. 2019; 24(1): 38-46. 
17 - Zink AG, Diniz MB, Santos MTBR, Guaré RO. Use of a Picture Exchange Communication System for Preventive Procedures in Individuals with Autism Spectrum Disorder: Pilot Study. Spec Care Dentist. 2016; 36(5): 254-259.

18 - Nelson TM, Sheller B, Friedman CS, Bernier R. Educational and Therapeutic Behavioral Approaches to Providing Dental care for Patients with Autism Spectrum Disorder. Spec Care Dentist. 2015; 35(3): 105-113.

19 - Nilchian F, Shakibaei F, Jarah ZT. Evaluation of Visual Pedagogy in Dental Check-ups and Preventive Practices Among 6-12-Year-Old Children with Autism. J Autism Dev Disord. 2017; 47(3): 858-864.

20 - Onol S, Kirzioglu Z. Evatuation of oral health status and influencial factors in chidren with autism. Niger J Clin Pract. 2018; 21(4): 429-435.

21 - Lai B, Milano M, Roberts MW. Unmet dental needs and barriers to dental Care among children with autism spectrum disorders. J Autism Dev Disord. 2012; 42(7): 1294-1303.

22 - Cagetti MG, Mastroberardino S, Campus G, Olivari B, Faggioli R, Lenti C, Strohmenger L. Dental Care Protocol based on Visual Supports for Children with Autism Spectrum Disorders. Med Oral Patol Oral Cir Bucal. 2015; 20(5): 598-604.

23 - Diário Oficial da União da República Federativa do Brasil [homepage on the internet] Lei n. 8.080/90. Dispõe sobre as condições para promoção, proteção e recuperação da saúde, a organização e o funcionamento dos serviços correspondentes e dá outras providências [Cited 2017 Sep 23]. Available from: http://www.planalto.gov.br/ccivil_03/leis/18080.htm

24 - Ministério da Saúde, Brasil. A saúde bucal no Sistema Único de Saúde. Brasília: Ministério da Saúde; 2018.

25 - Maltz M, Jardim JJ, Alves LS. Health Promotion and Dental Caries. Braz Oral Res. 2010; 24(1): 18-25.

26 - Santos DS, Mishima SM, Merhy EE. Work process in Family Health Program: the potential of subjectivity of care for reconfiguration of the care model. Ciência \& Saúde Coletiva. 2018; 23(3): 861-870.

27 - Mohsen T, Reg D. Making sense of Cronbach's Alpha. International Journal of Medical Education. 2011; 2: 53-55.

28 - Instituto Brasileiro de Geografia e Estatística. [homepage on the internet]. Censo demográfico - Amostra de pessoas com deficiência [Cited 2010]. Available from: https://cidades.ibge.gov.br/brasil/rn/ pesquisa/23/23612? detalhes=true.

29 - Ministério da Educação, Brasil. [homepage on the internet]. Portaria Interministerial, que Regulamenta o Decreto no 7.385, de 8 de dezembro de 2010, que instituiu o Sistema Universidade Aberta do Sistema Único de Saúde (UNA-SUS) [Cited 2013 Jul 10]. Available from: http://www. planalto.gov.br/ccivil_03/_Ato2007-2010/2010/Decreto/D7385.htm 
30 - Plataforma Arouca. [homepage on the internet]. Universidade Aberta do SUS [Cited 2018 May 01]. Available from: https:/www.unasus.gov.br/ cursos/plataforma_arouca.

31 - Lima L, Pires DEP, Novatzki EC, Medeiros F. Job satisfaction and dissatisfaction of primary health care professionals. Esc Anna Nery. 2014; 18(1):17-24.

32 - Gomes D, Gonçalves ASR, Pereira LS, Tavares RS, Pires DEP, Ramos FRS. Satisfaction and suffering in the work of dentist. RFO. 2010; 15(2): 104-110. 


\section{A necessidade do treinamento de cirurgiões- dentistas para $\mathrm{o}$ atendimento odontológico de pessoas com transtorno do espectro autista}

\section{Resumo}

Objetivos: o presente estudo teve como objetivo investigar a satisfação do cirurgião-dentista, a participação em cursos de capacitação, a atuação em serviços de atenção primária à saúde e a inclusão de pessoas com Transtorno do Espectro Autista (TEA) em consultório odontológico. Material e Métodos: 58 dentistas responderam a um questionário intitulado "Implementando uma Sistematização da Saúde Bucal para Pessoas com TEA aos Profissionais da Atenção Básica do Sistema de Saúde” que possuía quatro partes, e investigou a satisfação profissional, participação em cursos, atuação na atenção primária à saúde serviços em saúde pública e a inclusão de atendimento odontológico para pessoas com TEA. Resultados: $65,5 \%$ dos profissionais participaram de cursos de capacitação. Dentistas que realizaram cursos sobre pacientes com necessidades especiais afirmaram tratar significativamente mais pacientes com TEA ( $\mathrm{p}$-valor $=0,003$ ) e apontaram doença periodontal e cárie como os problemas mais frequentes. Porém, $89,6 \%$ desconheciam documento com diretrizes de prática clínica para pacientes autistas, reforçando a necessidade de capacitação profissional. Conclusão: Os cirurgiões-dentistas estão cientes da importância da capacitação e estão dispostos a realizar cursos que possam aprimorar sua atuação profissional na promoção da saúde bucal de pacientes com TEA.

PALAVRAS-CHAVE: Transtorno do espectro do autismo; Odontologia; Profissional de Saúde Pública; Educação.

\section{How to cite this paper}

Amaral LD, Azevedo TDPL, Moreira FCL, Lima AA, Bezerra ACB. The need for training dentists for dental care for people with autism spectrum disorder. Rev Odontol Bras Central 2021; 30(89): 403-421. DOI: 10.36065/robrac.v30i89.1555 